\title{
Padrões urbanos facilitadores da recarga de aquíferos
}

\author{
Aline da Nóbrega Oliveira ${ }^{\mathrm{a}} \oplus$, Sergio Koide $^{\mathrm{b}} \oplus^{\oplus}$,

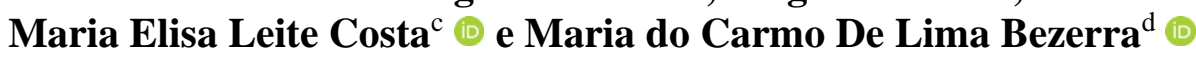 \\ ${ }^{a}$ Universidade de Brasília, Programa de Pós-Graduação em Arquitetura e Urbanismo, Brasília, DF, \\ Brasil. E-mail: aline.no@ hotmail.com \\ ${ }^{\mathrm{b}}$ Universidade de Brasília, Faculdade de Tecnologia, Departamento de Engenharia Civil e Ambiental, \\ Brasília, DF, Brasil. E-mail: skoide@unb.br \\ c Universidade de Brasília, Faculdade de Tecnologia, Departamento de Engenharia Civil e Ambiental, \\ Brasília, DF, Brasil. E-mail: mariaelisa@unb.br \\ ${ }^{d}$ Universidade de Brasília, Programa de Pós-Graduação em Arquitetura e Urbanismo, Brasília, DF, \\ Brasil. E-mail: mdclbezerra@gmail.com
}

Submetido em 20 de julho de 2019'. Aceito em 18 de dezembro de 2019.

\begin{abstract}
Resumo. A forma de ocupação do solo nas cidades, proveniente de padrões urbanisitcos que não dialogam com o meio físico, tem sido responsável por impactos no ciclo hidrológico devido a excessiva impermeabilização que contribui para diminuição da infiltração das águas e aumento de seu escoamento superficial. Nesse contexto, destaca-se a importância da análise e definição de metodologias de desenho urbnao que promovam padrões urbanos sensiveis a água. O presente trabalho estuda os fundamentos conceituais que explicam o funcionamento do ciclo hidrólógico para identificar padrões urbanos que reduzam o escomento superfical e os impactos sobre o meio fisico e construido nas cidades. Como método se utiliza :(i)Simulação do comportamento do escoamento superficial em área de pré urbanização;(ii) simulações realizadas em uma parcela urbana com projeto de loteamento com modelo tradicional adontando um padrão de urbanismo disperso; e (iii) simulação da mesma fração utilizando padrões urbanísticos sensiveis à águas previamente estudados. Como resultado se obteve que o escoamento superficial é bastante reduzido com proposta de urbanismo sensivel à agua, confirmando a relação entre o desenho urbano $e$ sua capacidade de garantir recarga de aquíferos.
\end{abstract}

Palavras-chave. recarga de aquíferos, escoamento superficial, padrões urbanos sensíveis à água, hidrologia.

\section{Introdução}

A noção de sustentabilidade, que remete a uma visão integrada entre ocupação e características do meio, indica que existe uma desconexão entre o planejamento urbano e a gestão dos recursos hídrícos nos processos de urbanização, o que propicia a diminuição da quantidade e qualidade das águas nas cidades.

A forma de ocupação urbana e sua crescente expansão são fatores que contribuem com impactos sobre o meio físico, pois o modelo predominante de ocupação do solo urbano possui foco no atendimento das demandas sociais e econômicas e desconsidera a base física do território. Esse fato resulta na interrupção de uma diversidade de serviços ecossistêmicos ${ }^{2}$ que a cidade necessita como insumo para seu funcionamento.

Os levantamentos e diagnósticos de reconhecimento do sitio, onde uma ocupação urbana se dará, possibilitam a identificação de particularidades sobre suas fragilidades que decorrem das associaçoes entre os fatores do meio fisico como hidrologia, geologia, solo e clima. Entretanto, na maioria dos 
casos, essa fragilidade não é considerada na definição da configuração de cidade proposta pelo projeto urbano.

Dentre os impactos ambientais urbanos se destacam aqueles relacionados à manutenção do ciclo hidrológico pelos grandes prejuizos que causam as populacões durante os picos climáticos. Esses processos são bem visiveis durante os alagamentos sobre as bacias que ocorrem devido a alta impermeabilização do solo e levam ao aumento da contaminação dos mananciais e a escassez hídrica. Decorrem das mudanças na capacidade de infiltração natural devido a alteração da camada superficial do solo que impede a recarga natural e que se reflete no fluxo de base dos reservatórios superficiais durante os períodos de estiagem.

Por tudo isso, um dos estudos para escolha de sítios para implantação de cidades se constituiu na análise hidrográfica: A água é um dos elementos fundamentais para a manutenção da vida e seu maior percentual, cerca de $97 \%$, se encontra em reservatórios subterrâneos, também denominados aquíferos, que são abastecidos por meio da infiltração no solo durante as precipitações. Os aquíferos são formações geológicas que permitem o movimento das águas de forma que essa água pode ser extraída ou descarregada em bacias superficiais (Seraphim,2018).

Essas correlações entre ocupação do solo e a alteração do ciclo hidrológico já seriam suficientes para se impor a necessidade de estudos sobre os padrões de ocupação que propiciem o melhor diálogo entre ocupação urbana e a água. O que se constata tanto na ocupação formal como informal nas cidades é uma desvalorização dos recursos naturais de forma geral e, em particular, os recursos hídricos subterrâneos, ao ocasionar a elevada impermeabilização do solo e impedir a infiltração das águas. Isso ocorre devido ao uso de modelos de urbanização de caráter disperso e com grandes áreas de sistema viário, áreas livres pavimentadas e/ou compactadas.

Assim, se resume o problema: a replicação de projetos urbanísticos tradicionais causa danos ao meio natural e impede a obtenção de serviços ambientais necessários ao fornecimento de água para abastecimento, o que passou nos últimsos anos a fazer parte do cotidiano das cidades brasileiras.

Hoje se sabe que a recorrente visão do senso comum de que a responsabilidade pelo baixo nivel dos reservatórios de abstecimento é a falta de chuvas nao é verdadeira, se for procedida uma análise de médio prazo e em um raio de ação que transceda o próprio reservatório. Pois o que ocorre é a ausência de planejamento hídríco em associação ao urbanístico. As precipitações dos períodos chuvosos de médio prazo são suficientes para, por meio da infiltração, abastecer os aquiferos e esses levariam a reservação da água para os longos períodos de seca.

Essas considerações levam a crer que a incorporação dos estudos de Ecologia e Hidrologia são essenciais ao Planejamento e Desenho Urbano, pois são necessários para consubstanciar uma configuração de ocupação, usos e funções mais apropriados a uma região (Ribas, 1988). Assim, entender e analisar os impactos da urbanização relacionados com a quantidade e qualidade da água representa um desafio ao Planejamento Urbano, demandando uma revisão das estratégias de ocupação do solo.

A busca por um desenho urbano de menor impacto, que inclua maior resiliência a infiltração natural das águas pluviais pode ser observada nos estudos precussores de Ian McHarg (1969) e, mais recentemente, nas técnicas do Low Impact Development $(\mathrm{LID})^{3}$. Esses estudos são voltados para qualificar estratégias de uso e ocupação do solo com foco nas características ambientais e na drenagem urbana que levam a análise de padrões urbanos que facilitem o manejo das águas no ambiente urbano.

Diante da existência de conhecimento sobre o funcionamento do ciclo hidrológico e dos impactos que geram a impermeabilização sobre o mesmo; e de estudos sobre técncias de controle do escoamento superficial e de padrão de ocuapção urbana que podem ser mais amigáveis a infiltração, o que se coloca como avanço no tema seria iniciar pesquisas sobre a simulação de arranjos morfológicos e de quantificação de seus resultados de modo a se ter informaçoes que possibilitem maior assertividade aos projetos urbanos. 
Essas razões fundamentam a escolha de uma área para uma análise quatitativa com teste de uso de um padrão de ocupação urbano que os estudos teóricos apontam como facilitador do aumento da infiltração da água e consequentemente da recarga de aquíferos. Foi escolhido o Distrito Federal (DF), que é uma região com baixo índice de águas superficiais e totalmente dependente da infiltração de suas chuvas para manutenção de seus reservatórios de abastecimento. Portanto, o trabalho busca testar um padrão de ocupação mais adequado a uma área de recarga de aquífero localizada em área de expansão urbana no DF, denominada de Setor Habitacional Taquari, trecho 2 (SHTq 2) na Região Administrativa do Lago Norte.

\section{Materiais e Métodos}

Primeiramente, foi realizada uma revisão bibliográfica envolvendo as temáticas de: (i) ocupação de áreas de recarga de aquíferos e o manejo do solo no processo de urbanização das cidades, pautados por Seraphim (2018); (ii) elementos que conformam os padrões urbanos discutidos por Panerai (2014) e (iii) as estratégias de ocupação urbana do Urbanismo sensível à água publicadas nos manuais do Low Impact Development (LID).

A sistematização desses conhecimentos foi essencial para conhecer as interrelações e utilizar o método de criação de cenários com diferentes padrões morfológicos para posterior simulação hidrológica. Utilizando os dados levantados na Companhia de Desenvolvimento do Distrito Federal (Terracap) foi delimitada uma fração do parcelamento proposto para a área de estudo pela Terracap, utilizando padrões urbanisticos tradiciaonais, a qual foi intitulada de cenário Terracap. Com uma área equivalente ao cenário Terracap, foi elaborado o cenário resiliente, pautado nas estratégias da base conceitual do urbanismo sensível à água e buscando a mitigação dos impactos da impermeabilizaçao do solo. Como forma de cenário de controle para estudo da recarga de aquíferos em sua condição atual foi criado um terceiro cenário, em que se simulou a mesma área dos demais cenários com características de préurbanização, ou seja, um cenário com características naturais, sem nenhum tipo de interferência urbana sobre o solo.
Para analisar o padrão de menor impacto para as áreas de recarga de aquíferos no processo de urbanização da região da área de estudo, foram utilizados softwares de: (i) CAD e SIG para análise dos padrões urbanos do cenário Terracap e elaboração do cenário resiliente e natural; (ii) modelagem hidrológica pelo Storm Water Management Model (SWMM)

\section{A relação entre padrões urbanos e recarga de aquíferos}

Para entender como os padrões de urbanização podem alterar o ciclo hidrológico, procurou-se identificar os impactos recorrentes sobre o manejo do solo urbano nos processos de urbanização. Estudos de Seraphim (2018) apontam que as alterações no manejo do solo urbano nos processos de urbanização podem causar os seguintes impactos: compactação do solo, remoção da camada arbórea nativa, selamento por superfícies impermeáveis

O impacto por compactação do solo está associado ao processo inicial da concepção de loteamentos e cidades. Durante os procedimentos de terraplanagem, para edificar as áreas urbanas, a excessiva perturbação afeta as propriedades do solo, como sua condutividade e porosidade, que impacta na permeabilidade e na movimentação das águas no solo. Esse impacto também pode ser ocasionado em áreas sem cobertura vegetal em que há passagem recorrente de veículos, transeuntes. As primeiras camadas do solo compactam- se e suas taxas de infiltração ficam reduzidas.

A compactação do solo urbano ao alterar a estrutura do solo pode até impedir o crescimento de vegetação e a penetração das raízes. Existe, ainda, uma expectativa de que a compactação do solo urbano diminua com o tempo desde que foi perturbado mas somente com a redução do uso do solo, o que pode levar décadas para que essa reversão ocorra.

Já o impacto de remoção da vegetação arbórea nativa é comum no processo de ocupação urbana, pois os estratos nativos são substituídos por grandes áreas de solos expostos ou com o uso de gramíneas. A vegetação nativa, principalmente a arbórea, é responsável pela retenção das águas no solo. Espécies como as do cerrado, que possuem 
raízes profundas, aumentam a capacidade de retenção das águas infiltradas no solo. Kays (1980), já indicava que uma área coberta por superfícies impermeáveis, que correspondia a $27,1 \%$, entretanto a maior parte da vegetação nativa havia sido removida e substituída por solos e gramíneas, o que ocasionou uma redução da infiltração 30 vezes maior que nas áreas onde havia floresta nativa.

Já o impacto do selamento por superfícies impermeáveis consiste na implantação dos elementos que são construídos com materiais de alta impermeabilidade, os quais reduzem a zero a infiltração das águas, como as calçadas, vias, ruas, estacionamentos, pátios, edificações, piscinas, quadras de esportes etc. O selamento do solo impede a infiltração das águas durante a precipitação e o abastecimento dos aquíferos, além de aumentar a vazão de pico nas chuvas e o escoamento superficial. Esse impacto é uma agravante, pois consiste nos elementos que compõem o tecido urbano, os quais podem, com os estudos propostos pela lógica do urbanismo sensível à água e identificados nas análises dos manuais do Low Impact
Development, auxiliar na construção de estratégias de padrões promotores para o aumento da infiltração das águas precipitadas.

\section{Elementos urbanos e as estratégias do urbanismo sensível à água}

A partir de uma leitura dos elementos urbanos que constituem a configuração das cidades com base em Panerai (2014), foram identificados os elementos que mais se relacionam com os manejos do solo acima referidos, tendo se chegado a seguinte classificação que envolve, de forma geral, as diferentes formas de ocupaçao do solo: (i) rede viária (inclui calçadas, ciclovias, rede de drenagem) (ii) parcelamentos fundiários (inclui as edificações); (iii) espaços públicos (praças, parques, áreas de preservação, espaços livres). A titulo de exemplificação, pode ser feita uma breve correlação com os impactos do manejo do solo urbano, a fim de relacionar quais impactos são causados nesses ambientes, conforme demonstra o Quadro 1.

Quadro 1. Elementos urbanos e impactos do manejo do solo (fonte: elaborado pelos autores com base em estudos de Seraphim, 2018)

\begin{tabular}{lc}
\hline Elementos Urbanos & Impactos à Infiltração \\
\hline Parcelamentos fundiários & Redução da Vegetação Nativa; \\
& Compactação do Solo; \\
Espaços Públicos & Redamento do Solo. \\
\hline & Compactação do Solo. \\
Rede Viária & Redução da Vegetação Nativa; \\
& Compactação do Solo; \\
& Selamento do Solo. \\
\hline
\end{tabular}

A partir das análises aos condicionantes que geram os impactos sobre os ambientes urbanos e os estudos realizados pelos manuais do Low Impact Development, foram elaboradas estratégias de mitigação dos impactos e mecanismos para melhoria da infiltração.

No quesito dos parcelamentos fundiários, as construções, que geram a impermeabilização, devem ser contíguas às áreas de permeabilidade, para que as águas provenientes das precipitações sejam escoadas para elas e assim diminua o escoamento lançado para a rede viária, elemento altamente impermeável.

Outra questão é em relação a uma região em que há uma ocupação residencial unifamiliar, a densidade populacional é menor por área 
do que em uma ocupação multifamiliar, que em um mesmo lote pode ser alocado um edifício que comporte mais famílias, em detrimento de uma residência com um núcleo familiar. Essa relação leva a crer que o uso de residências multifamiliares, mantendo-se a densidade populacional, possibilita o uso de mais espaços públicos que podem levar ao aumento da infiltração e ao mesmo tempo disponibilizar mais espacos de interação social, contribuindo para qualidade de vida e ambiental da população.

Os espaços públicos e a rede viária desempenham muitas funções nas cidades: são áreas de lazer, integração, circulação e conexão entre os espaços, atividades e pessoas. Podem ser caracterizados pelas praças, pátios, largos, passeios, esplanadas, bulevares, avenidas, ruas, canteiros etc. Esses ambientes podem auxiliar na captação das águas pluviais para infiltração com o uso de sistemas de drenagem sustentável, os quais promovem a retenção e detenção das águas escoadas e posterior infiltração auxiliando, ainda mais, na manutenção do ciclo hidrológico. Esses elementos de infiltração possuem grande valor cênico e podem compor os mais diferentes espaços urbanos.

Para que os espaços públicos e a rede viária auxiliem na promoção da infiltração das águas, somente com estratégias que se refiram aos padrões urbanisticos de ocupação, os elementos devem estar dispostos em relação as curvas de nível, as linhas de drenagem, utilizar o plantio de vegetação nativa e estarem articulados com a paisagem natural, de modo a propiciar maior retenção das águas no solo. A rede viária deve ser desenhada com padrão hibrido, o qual articula o desenho em grelha com o curvilíneo, proporcionando a conectividade, mas diminuindo a ocupação de áreas impermeáveis que o sistema grelha promove. O uso misto desses padrões deve-se creditar ao fato de que a grelha promove mais impermeabilização, mas por outro lado, gera um ambiente mais conectado

Os materiais construtivos que conformam esses espaços, também, devem buscar a resiliência com a infiltração das águas e a mitigação dos impactos, com a utilização de pavimentos que geram maior permeabilidade.
No Quadro 2 se apresentam procedimentos para construçao de padrões que facilitem a infiltração das águas, promovendo um planejamento resiliente. Procurou-se ordenar as sugestões por elemento de composição do tecido urbano.

Diante desses estudos, foram elaborados os cenários reais para simulação hidrológica dos percentuais de infiltração das águas que se obtém com diferentes configurações urbanas.

\section{Sobre a área de estudo}

Avançar na quantificação do que se perde de recarga natural de águas subterrâneas com os diferentes tipos de ocupação do solo urbano é uma informação chave à gestão integrada dos recursos hídricos, mas ainda pouco estudada no cerrado (Santos; Koide, 2016). No caso do Distrito Federal, esse fato se agrava quando se sabe que a região é conhecida como o berço das águas, devido ao aporte significativo de nascentes responsáveis pela formação de rios, que contribuem para três das principais bacias hidrográficas do país, e, no entanto, vem sendo ocupado por estruturas urbanas que não dialogam com o sítio físico da região e impactam de forma direta o ciclo hidrológico.

O Setor Habitacional Taquari trecho 2, escolhido para o estudo, é uma área delimitada como Zona de Expansão Urbana desde a década de 1980, quando Lúcio Costa a previu no documento Brasília Revisitada, de 1987. Hoje consta como tal do Plano Diretor de Ordenamento Territorial do Distrito Federal -PDOT, 2012.

Nessa mesma década de sua indicação como possivel área de expansão urbana, Ribas (1988) estudou a área e apontou a necessidade de uma melhor articulação das características ambientais com os padrões de ocupação. Havia indicado a área como sensivel a vários fatores ambientais, incluisve à água. Na época, utlizou um método cartográfico de planejamento ambiental denominado Análise de Risco Ecológico ${ }^{\text {iv }}$ mas não chegou a fazer análises quantitativas. Cerca de 30 anos depois, nos estudos para o Zoneamento Ecológico Econômico realizado pelo Governo do Distrito Federal, a área do SHTq 2 foi considerada uma região com elevada 
sensibilidade à recarga de aquíferos, comprovando as colocações de Ribas.

Hoje, como já referido, a região possui um projeto de parcelamento urbano de baixa densidade, com estimativa populacional de seis mil habitantes, em uma área de aproximadamente 224 hectares, elaborado pela Terracap. O projeto foi vetado pelo Ministério Público em resposta às denúncias de órgãos ambientais e sociedade civil diante dos possíveis impactos sobre a área de recarga de aquíferos e outros aspectos do meio fisico biótico desconsiderados. Ademais, o projeto contraria a Resolução $n^{\circ}$ 09 de 2011 da Agência Controladora de Águas (ADASA) que exige um lançamento máximo das águas pluviais no corpo receptor de 24,4 1.s/hac, sendo que o parcelamento proposto supera esse limite. Esse dado já comprova que a proposta urbana precisa ser revista e um novo padrão de ocupação, que aumente a infiltração das águas, seja implantado

Quadro 2. Elementos urbanos e impactos do manejo do solo (fonte: elaborado pelos autores).

\begin{tabular}{|c|c|c|c|}
\hline $\begin{array}{l}\text { Elementos } \\
\text { Urbanos }\end{array}$ & $\begin{array}{l}\text { Impactos à } \\
\text { Infiltração }\end{array}$ & Estratégias & $\begin{array}{l}\text { Procedimentos nos } \\
\text { Padrões urbanos }\end{array}$ \\
\hline $\begin{array}{l}\text { Parcelamentos } \\
\text { fundiários }\end{array}$ & $\begin{array}{c}\text { Redução da } \\
\text { Vegetação Nativa; } \\
\text { Compactação do } \\
\text { Solo; } \\
\text { Selamento do Solo. }\end{array}$ & $\begin{array}{c}\text { Promover o aumento da } \\
\text { permeabilidade das águas } \\
\text { pluviais; } \\
\text { Direcionar o escoamento } \\
\text { para zonas vegetadas; } \\
\text { Preservar vegetação nativa; } \\
\text { Locar técnicas } \\
\text { compensatórias em áreas de } \\
\text { captação das águas }\end{array}$ & $\begin{array}{l}\text { Baixa taxa de ocupação; } \\
\text { Aumento do coeficiente de } \\
\text { aproveitamento do lote; } \\
\text { Construções verticais; } \\
\text { Substituição das áreas } \\
\text { impermeáveis por } \\
\text { vegetação nativa. }\end{array}$ \\
\hline $\begin{array}{l}\text { Espaços } \\
\text { Públicos }\end{array}$ & $\begin{array}{l}\text { Redução da } \\
\text { Vegetação nativa; } \\
\text { Compactação do } \\
\text { Solo. }\end{array}$ & $\begin{array}{l}\text { Preservar vegetação nativa; } \\
\text { Locar Técnicas } \\
\text { compensatórias em áreas de } \\
\text { captação das águas }\end{array}$ & $\begin{array}{l}\text { Implantar técnicas de } \\
\text { drenagem urbana } \\
\text { sustentável integradas a } \\
\text { paisagem; } \\
\text { Utilizar superfícies com } \\
\text { maior permeabilidade. }\end{array}$ \\
\hline Rede Viária & $\begin{array}{c}\text { Redução da } \\
\text { Vegetação Nativa; } \\
\text { Compactação do } \\
\text { Solo; } \\
\text { Selamento do Solo. }\end{array}$ & $\begin{array}{c}\text { Reduzir área de sistema } \\
\text { viário; } \\
\text { Uso de traçados viários } \\
\text { híbridos; } \\
\text { Alinhar vias às curvas de } \\
\text { nível; } \\
\text { Direcionar escoamento para } \\
\text { zonas vegetadas. }\end{array}$ & $\begin{array}{l}\text { Padrão híbrido: viário } \\
\text { curvilíneo e grelha; } \\
\text { Dispositivo de drenagem } \\
\text { sustentável nos canteiros. }\end{array}$ \\
\hline
\end{tabular}

\section{Modelagem hidrológica da infiltração}

A fim de quantificar os impactos do projeto urbanístico proposto para o SHTq 2 e, averiguar a aplicabilidade e funcionalidade dos procedimentos listados no Quadro 2, para o estabelecimento de padrões urbanos mais resilientes à agua, foi realizada a simulação hidrológica dos cenários referidos anteriormente.
Utilizou-se uma fração do parcelamento do SHTq2 para elaborar modelos para as simulações hidrológicas. Apesar da simulação se realizar em uma pequena fração, Silva (2017) aponta que o uso de modelo para representação da realidade é um método válido de compreensão e avaliação do comportamento de um conjunto maior, desde que esse guarde similaridade com o todo e se realizem extrapolações. 
No âmbito da drenagem urbana, o modelo tem o objetivo de representar o escoamento da precipitação pela superfície do terreno, interceptação, infiltração, evapotranspiração e como esses processos interagem com a rede de drenagem de águas pluviais (Cabral et al., 2009).

\section{Método de simulação}

Para realização das simulações dos três cenários: (i) Cenário pré-urbanização; (ii) Cenário Terracap e (iii) Cenário Resiliente, foi utlizado o modelo Storm Water Management Model (SWMM), que se mostrou adequado à simulação dos processos hidrológicos de uma área urbana, sendo uma ferramenta muito útil para estudos de manejo de águas pluviais (Carvalho, 2018). O programa utilizado foi o software PCSWMM, desenvolvido pela CHIWATER ${ }^{5}$, que é um modelo dinâmico chuva-vazão. Foi considerada uma chuva de projeto para simulação, com tempo de retorno (TR) de 10 anos. Essa chuva é indicada pela NOVACAP (Companhia Urbanizadora da Nova Capital) e foi utilizada para os estudos e propostas de projetos de drengem pelo Plano diretor de drenagem Urbana do Distrito Federal de 2009. Em relação à infiltração, o PCSWMM permite a escolha de diversos métodos para simular e nesse trabalho foi utilizado o método SCS (Soil Conservation Service) que se vale do conceito de curva número para cálculo de infiltração.

A curva número $(\mathrm{CN})$ é um índice que representa a combinação empírica de três fatores: grupo do solo, cobertura do solo e condições de umidade antecedente do solo (McCuen, 1998 apud Tomaz, 2011). Baseado nos levantamentos de características pedológicas, o tipo de solo encontrado na área de estudo é o latossolo, que se classifica, no método, como solo tipo "A": solos que produzem baixo escoamento superficial e alta infiltração (Tucci et al, 1993 apud Tomaz, 2011).

Para criação dos cenários, a parcela selecionada da totalidade do parcelamento foi de aproximadamente 3,33 hectares, como mostra o recorte da Figura 1.

Para simulação do Cenário 1 , foi considerada a área da parcela do loteamento sem nenhum tipo de ocupação urbana, com cobertura vegetal tipo campo, ou seja, não foram incluídas na simulação indicações de floresta ou cerrado nativo, pois a área é atualmente modificada. O CN utilizado neste cenário corresponde a 39 , que indica uma superfície de vegetação rasteira em mais de $75 \%$ de sua área. Este cenário representará o processo de infiltração natural sem urbanização. O que encontraremos será a infiltração e o escoamento superficial que esse tipo de cobertura do solo gera.

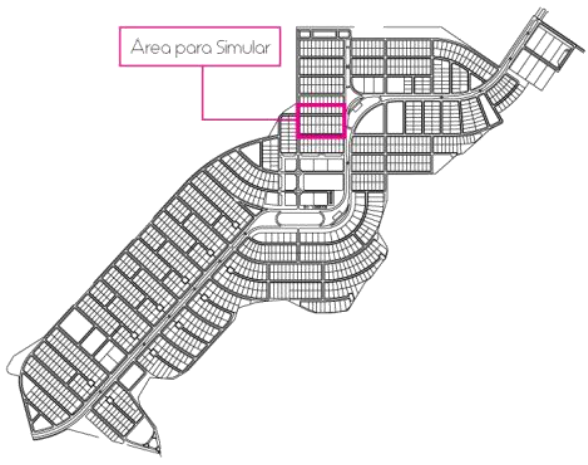

Figura 1. Parcela simulada projeto Terracap. Dimensões 230mx145m (fonte: elaborada pelos autores).

Para o cenário 2 foi simulado os padrões urbanisticos tipicos de um parcelamento tradicional, compreendendo os seguintes elementos urbanos: vias, calçadas, lotes. No lote foi considerada a área ocupada pela edificação e ás áreas que devem permanecer permeáveis, ou seja, o percentual de taxa de permeabilidade previsto pelas normas.

Para separar a área ocupada da não ocupada e determinar o $\mathrm{CN}$ para este cenário, foi utilizado a Norma de Gabarito 111/99 (NGB), que elenca os parâmetros urbanos do SHTq 2, chegando aos CN's de: (i) 98 para áreas ocupadas por edificação no lote, via coletora, via local e calçadas; e (ii) 49 para as áreas permeáveis no lote. A Figura 2 apresenta o modelo do cenário 2 simulado.

A parcela simulada corresponde ao total de 33 lotes unifamiliares, ou seja, 33 famílias ocupantes na parcela.

Para o cenário 3 , assim como nos outros, foi considerada a mesma dimensão da fração. Os lotes, vias e calçadas propostos pela Terracap foram removidos e substituídos por projeções com polígonos que correspondem, respectivamente, a: (i) ocupações multifamiliares; (ii) vias; e (iii). as áreas públicas que antes eram ocupadas por áreas particulares de lotes com grande tendência a tornarem-se impermeáveis. 


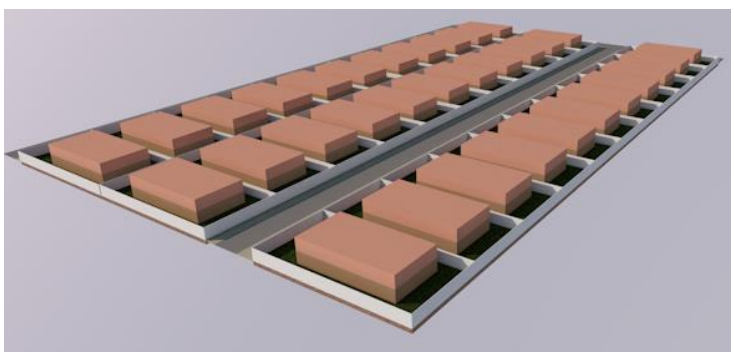

Figura 2. Parcela simulada Cenário 2. Padrão Terracap (fonte: elaborada pelos autores).

Se for considerado um edifício de 6 pavimentos, com três apartamentos por andar, com média de $300 \mathrm{~m}^{2}$ cada (as demais áreas, dos $1200 \mathrm{~m}^{2}$, destinadas a circulação vertical), e considerando as seis projeções, seriam 108 famílias residindo na área correspondente a fração estudada.

A substituição de padrão unifamiliar para multifamiliar ocasionou o aumento das áreas permeáveis e, também, da densidade populacional. A figura a seguir apresenta a configuração do cenário 3 :

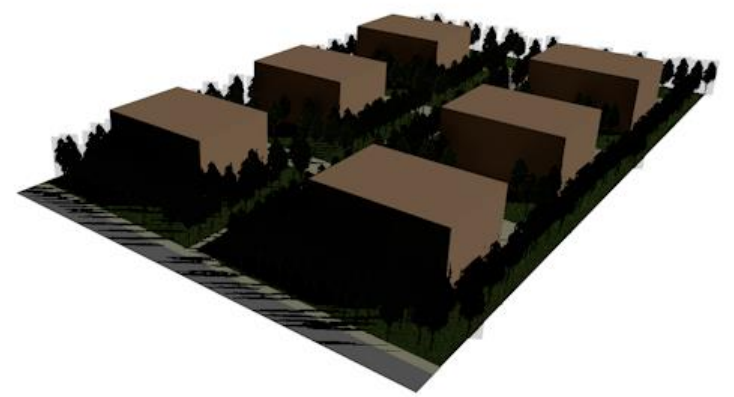

Figura 3. Parcela simulada cenário 3. Padrão resiliente (fonte: elaborada pelos autores).

Também foi considerada uma alteração no $\mathrm{CN}$ dos pavimentos das calçadas, vias coletoras, locais e estacionamentos, pois, de acordo com o Quadro 2 esses deveriam possuir pavimentos com maior permeabilidade, ou pavimentos porosos, pisogramas ou pisos em paralelepípedos, que permitem maior infiltração. Para este aumento foi necessária a indicação do $\mathrm{CN} 76$ para calçadas e vias locais, o que significa um aumento da permeabilidade. Sendo assim, para este cenário 3 os CN's utilizados foram: (i) 98 para áreas ocupadas pelas projeções edilícias e via coletora; (ii) 76 para via local e calçadas; e (iii) 39 para para os espaços livres permeáveis.

\section{Resultados e Conclusões}

Na Figura 4 são apresentados os resultados das simulações por cenários:

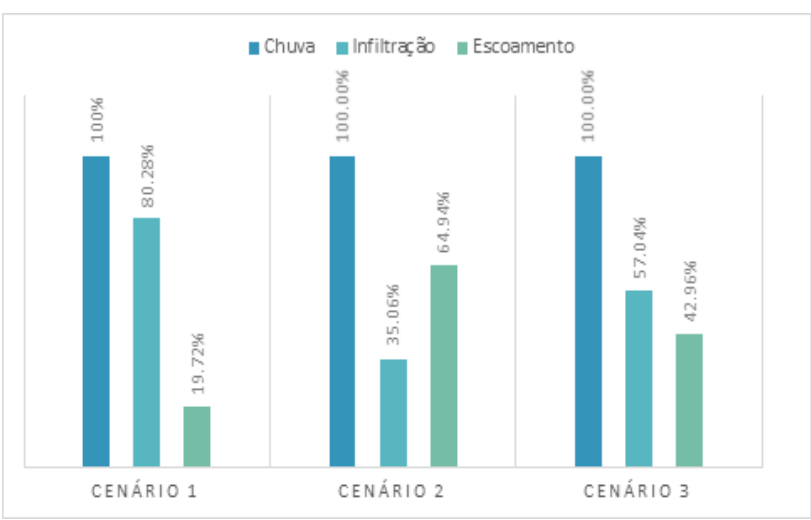

Figura 4. Gráfico com percentual de escoamento superficial, infiltração e chuva simulada (fonte: elaborada pelos autores).

Como pode ser verificado, o cenário 1 , com características de pré-urbanização, obteve o maior percentual de infiltração, $80,28 \%$ da chuva infiltrada. Entre os cenários 2 e 3, percebe-se que no cenário 3- parcelamento resiliente, com estratégias de urbanismo sensível à água e teve uma infiltração cerca de $20 \%$ maior do que a do cenário 2parcelamento padrão Terracap.

As simulações realizadas, utilizando padrões urbanísticos sensíveis à água, demonstraram que é possível ocupar uma zona de expansão urbana com sensibilidade à recarga de aquíferos e aumentar o potencial de infiltração. Os estudos e a metodologia desenvolvida possibilitam tornar claras as interfaces e as estratégias a serem utilizadas para que os padrões urbanísticos sejam utilizados, não por uma questão de estilo urbanistico ou 'moda', mas por sua adequação às características do sítio.

Certamente esse tipo de estudo deve ampliar a avaliação de padrões urbanos, relacionando-se, inclusive, com outros critérios de desempenho do espaço urbano, tal como integração social, para que, de forma associada, se chegue a padrões que possam atender a mais de um objetivo de sustentabildiade urbana.

A metodologia comprovou sua aplicabilidade aos estudos urbanos, o que resulta em uma integração entre as áreas do planejamento urbano e do manejo de águas pluviais, de onde o método de simulação utilizado é originário. 


\section{Agradecimentos}

Os autores agradecem à Universidade de Brasília pelo apoio na elaboração deste trabalho.

\section{Notas}

${ }^{1}$ Este artigo foi submetido originalmente até $\mathrm{o}$ prazo de 20 de julho de 2019 ao PNUM 2019 Maringá. A seleção dos artigos foi feita pelos editores desta seção temática entre 24 de agosto e 29 de outubro de 2019. As versões revisadas foram enviadas até o dia 10 de dezembro de 2019.

${ }^{2}$ Entende-se por serviços ecossistêmicos bens que são fornecidos pela natureza, direta ou indiretamente, para manutenção do planeta. A critério de exemplo temos a água, a qual é purificada pelos ecossistemas e ação antrópica prejudica esse fornecimento.

\section{Referências}

Cabral, J.J.S.P., Mascarenhas, F.B., Castro, M.A.H.; Miguez, M.G., Peplau, G.R. \& Bezerra A.A. (2009) Modelos Computacionais para Drenagem Urbana. Em: Righetto, M. A. (ed.) Manejo de Águas Pluviais Urbanas. Rio de Janeiro, Associação Brasileira de Engenharia Sanitária e Ambiental (ABES), pp. 112-148.

Carvalho, D. J. (2018) Manejo de Águas Pluviais Urbanas em Diferentes Projetos Urbanísticos e com Soluções de Baixo Impacto para Área Residencial - Taquari/DF. Monografia de graduação não publicada. Faculdade de Tecnologia, Universidade de Brasília, Brasília.

Kays, B. L. (1980) Relationship of forest destruction and soil disturbance to increased flooding in suburban North Carolina piedmont. Em METRIA 3-Proceedings of the Third Conference of the Metropolitan Tree Improvement Alliance, 1980, junho 18-20, Rutgers State University of New Jersey, New Jersey, Forest Service. pp. 118125.

McHarg, I. L. (1969) Design with nature. New York, American Museum of Natural History.

Ribas, O. T. (1988) Critérios e diretrizes de planejamento e desenho urbano para asa nova norte (área F), do plano urbanístico "Brasilia

\begin{abstract}
${ }^{3}$ Projetos e planejamento hídrico do escoamento superficial de águas pluviais com base no manejo de baixo impacto, utilizando técnicas de engenharia hidrológica aliada à paisagem.

iv Ver artigo Articulação entre Ambiental e Urbanização: Estudo da ARIE JK no Distrito Federal (Chaer; Palmeira, 2019)
\end{abstract}

${ }^{5}$ A companhia Chiwater, canadense, forneceu a licença estudantil para elaboração desta pesquisa de âmbito acadêmico.

Revisitada" visando a minimização dos impactos sobre o meio ambiente natural. Monografia de graduação não publicada. Faculdade de Arquitetura e Urbanismo, Universidade de Brasília, Brasília.

Santos, R. M. \& Koide, S. (2016) Avaliação da Recarga de Águas Subterrâneas em Ambiente de Cerrado com Base em Modelagem Numérica do Fluxo em Meio Poroso Saturado. Revista Brasileira de Recursos Hídricos (RBRH), 21, (2), 451-465. Disponível em: http://dx.doi.org/10.21168/rbrh.v21n2.p451-465

Seraphim, A. P. A. C. C. (2018) Planejamento urbano e a gestão das águas na cidade: Relação entre tipologias de ocupação urbana e recarga de aquíferos no Distrito Federal. Monografia de graduação não publicada. Faculdade de Arquitetura e Urbanismo, Universidade de Brasília, Brasília.

Silva, T. J. B. (2017) Avaliação da rede de drenagem urbana do Setor Habitacional Taquari. Monografia de graduação não publicada. Faculdade de Tecnologia, Universidade de Brasília, Brasília.

Tomaz, P. (2011) Cálculos Hidrológicos e Hidráulicos para Obras Municipais. São Paulo, Navegar. 


\section{Tradução do título, resumo e palavras-chave}

Urban patterns facilitating aquifer recharge

Abstract. The form of land occupation in cities, resulting from urban patterns that do not dialogue with the physical environment, has been responsible for impacts on the hydrological cycle due to excessive waterproofing that contributes to the reduction of water infiltration and increased surface runoff. In this context, the importance of analyzing and defining urban design methodologies that promote watersensitive urban patterns is highlighted. The present work studies the conceptual foundations that explain the functioning of the hydrologic cycle to identify urban patterns that reduce the superficial space and the impacts on the physical and built environment in the cities. The method used is: (i) Simulation of runoff behavior in a pre-urbanization area, (ii) simulations carried out in an urban plot with a traditional model allotment project with a dispersed urbanism pattern, and (iii) simulation of the same fraction using watersensitive urban patterns previously studied. As a result, it was obtained that the surface runoff is greatly reduced with a proposal for water-sensitive urbanism, confirming the relationship between urban design and its ability to ensure aquifer recharge.

Keywords. urbanization, aquifer recharge, urban patterns, hydrology.

Editor responsável pela submissão: Renato Saboya.

Licenciado sob uma licença Creative Commons. 